\title{
Water retention and transfer properties of a Green roof volcanic substrate
}

\author{
Filip Stanic ${ }^{1}$, Pierre Delage ${ }^{2 *}$, Yu Jun $\mathrm{CUI}^{1}$, Emmanuel DE LAURE $^{1}$ \\ ${ }^{1}$ Ecole des Ponts ParisTech, Navier/CERMES, F 77455 Marne la Vallée, France \\ ${ }^{2}$ Ecole des Ponts ParisTech, HMCo, F 77455 Marne la Vallée, France
}

\begin{abstract}
The water retention curve and the hydraulic conductivity function of a volcanic coarse granular material used as a substrate in an urban green roof in the Paris area was carried out on a newly developed device, in which low suctions were controlled. In the same cell, a hanging column system was used for controlling smaller suctions (up to $32 \mathrm{kPa}$ ) and the axis translation technique for larger suctions (up to 50 $k P a$ ). Water exchanges were monitored in connected tubes by using a high accuracy differential pressure transducer. The step changes in suction were also used to determine the hydraulic conductivity function by means of Gardner's method, accounting for the impedance effects due to the high air entry value ceramic porous disk with Kunze and Kirkham's method. van Genuchten and Brooks and Corey models were used for the water retention curve, but the hydraulic conductivity functions derived from these expressions appeared to lead to a significant under-estimation, confirming the need of operational and simple device for the experimental determination of the hydraulic conductivity function.
\end{abstract}

\section{Introduction}

Urban green roofs are used to reduce both the urban heat island that characterize cities (thanks to the evapotranspiration of vegetation) and urban run-off. Their substrates have to be light enough and present satisfactory water retention and transfer properties, which is the case of the coarse volcanic granular substrates used in the "Green Wave" of the Bienvenüe building (Versini et al. 2017) [1], located close to Ecole des Ponts ParisTech, $18 \mathrm{~km}$ east of Paris. To better understand the hydrological contribution of the green roof, its water retention and transfer properties have been experimentally investigated through a new experimental device adapted for coarse material.

\section{Materials and methods}

\subsection{Material}

The coarse volcanic material (VulkaTec Riebensahm GmbH 2016, Germany; www.vulkatec.de) is presented in the photo of Figure 1, and its main characteristics in Table 1 . The grain density was determined by using water pycnometer, providing an average value of 2.35 $\mathrm{Mg} / \mathrm{m}^{3}$, a small value compatible with the volcanic origin of the material. The dry density of the sample tested was determined by calculating its volume (from its dimensions) and measuring its weight, providing a value of $1.42 \mathrm{Mg} / \mathrm{m}^{3}$, light enough not to load the roof significantly. The resulting porosity was found equal to
0.395 , with a percentage of $4 \%$ of organic matter, determined by using the French standard XPP94-047 1998 [2] (that consists in comparing the sample weight before and after heating at least 3 hours at temperature between 450 and $500{ }^{\circ} \mathrm{C}$ ). The grain size distribution curve of the substrate, determined by sieving following the French standard NFP94-056 (1996) [3] is presented in Figure 2. Only the particles with diameter smaller than $6 \mathrm{~mm}$ have been kept for testing (dotted red curve), given that the specimen was tested in a $70 \mathrm{~mm}$ diameter cell. The size of particles smaller than $80 \mu \mathrm{m}$ have been measured by sedimentation (NFP94-057 - 1992) [4].

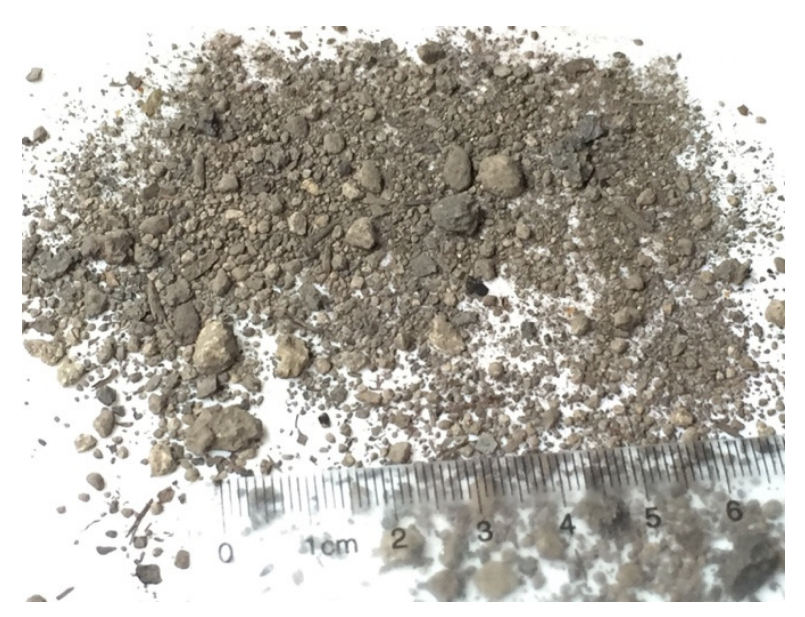

Fig. 1. Photo of the volcanic material.

*Corresponding author: pierre.delage@enpc.fr 
Table 1. Characteristics of the volcanic material.

\begin{tabular}{|c|c|c|c|}
\hline $\begin{array}{c}\text { Grain } \\
\text { density } \\
\mathrm{Mg} / \mathrm{m}^{3}\end{array}$ & $\begin{array}{c}\text { Dry } \\
\text { density } \\
\mathrm{Mg} / \mathrm{m}^{3}\end{array}$ & $\begin{array}{c}\text { Porosity } \\
\%\end{array}$ & $\begin{array}{c}\text { Organic } \\
\text { matter } \\
\%\end{array}$ \\
\hline 2.35 & 1.42 & 39.5 & 4 \\
\hline
\end{tabular}

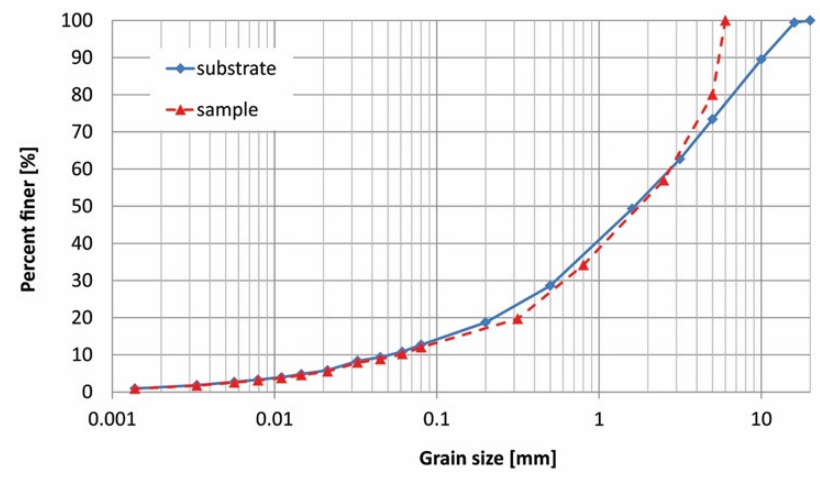

Fig. 2. Grain size distribution curve of the volcanic material.

\subsection{Methods of controlling suction}

\subsubsection{Hanging column method}

The hanging column technique was adopted because of its simplicity to use and of its good accuracy in both the control of low suctions (typical of coarse materials) and the measurement of water exchanges. Its implementation is presented in Figure 3, in which one can observe that a $70 \mathrm{~mm}$ diameter cylindrical cell is connected at its base through valve $\mathrm{V} 2$ to an outlet controlled by valve V3 and to a water reservoir through valve V1. The cell is also connected through a central tube to a mobile device that allows imposing water levels lower than that of the sample, so as to apply suctions defined by the difference in water level between the sample and the mobile part (up to $32 \mathrm{kPa}$ at the maximum height of $3.2 \mathrm{~m}$ ).

The mobile device contains a smaller inner glass tube (diameter $\left.\mathrm{d}_{\text {inn }}=0.5 \mathrm{~cm}\right)$ and a larger outer glass tube $\left(\mathrm{d}_{\text {out }}\right.$ $=1.5 \mathrm{~cm}$ ). The inner tube is connected to the sample while the differential pressure transducer is connecting the outer tube with the reference glass tube. This pressure transducer $(0.1 \mathrm{~mm}$ accuracy in water height) provides high frequency measurements (every $10 \mathrm{~s}$ ) necessary for determining the hydraulic conductivity function. The change in capillary potential is detected as the height difference between the water levels either in the inner (valve V4 opened) or the outer tube (valve V5 opened), and the constant reference water level in the reference tube.

Once the specimen carefully saturated, two methods were used to impose suction. Since a significant amount of water was extracted at smaller suctions, suction was imposed by closing valves V2 and V5, by filling the inner tube up to the top and by moving down the mobile device at a position corresponding to the required suction ( $h_{\mathrm{k}}$ in Fig. 3). Valves V2 and V5 were then opened, resulting in water being extracted from the sample under the effect of increased suction. The extracted volume of water ( $\Delta V$ in Fig. 3 ) flows from the top of the inner tube into the outer tube and is monitored by the differential pressure transducer that measures the height difference between the water levels in the outer and reference tubes. Once equilibrium is reached (after $6-24$ hours), a point on the WRC is obtained by calculating the resulting change in water content.

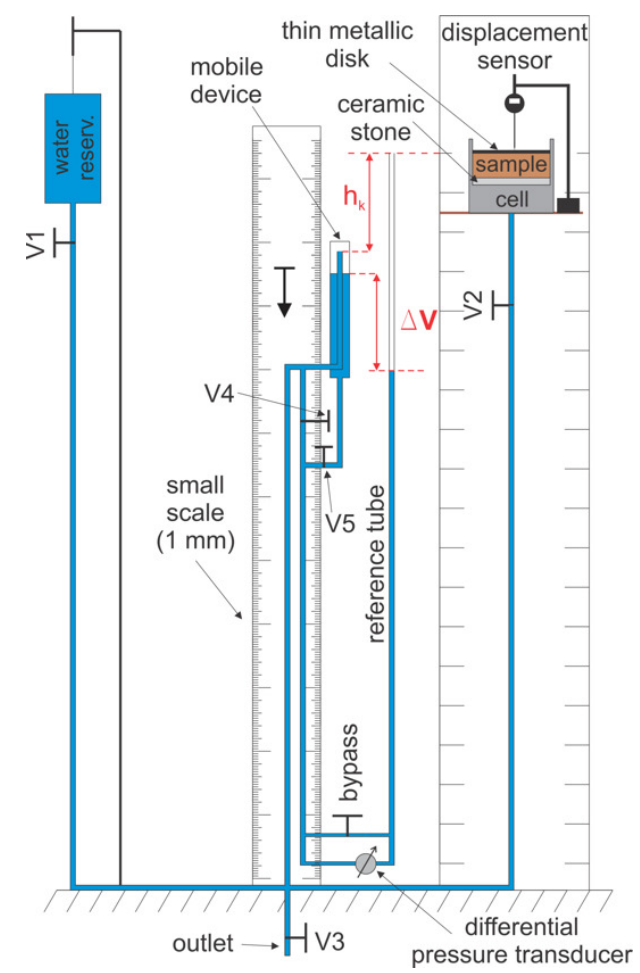

Fig. 3. Hanging column system.

Given that less water was extracted at larger suctions, the volume changes were monitored through the changes in level of the water in the inner tube (that was no longer previously adjusted at maximum level) by means of the pressure transducer (with valve V5 closed and V4 opened).

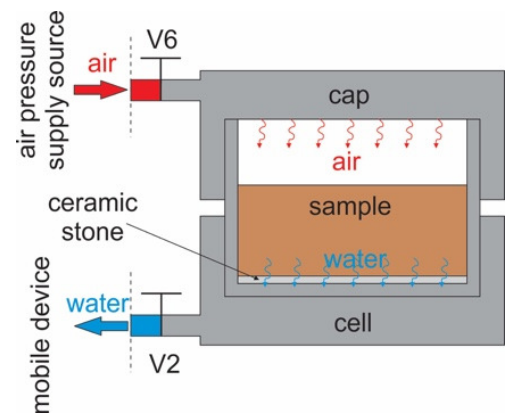

Fig. 4. Cap used to apply the axis translation method.

\subsubsection{Axis translation technique}

Air pressure was applied by using a cap placed on the specimen and connected to an air pressure supply source (Figure 4). The sample and the mobile device were kept at the same level, above the differential pressure transducer, in order to monitor the changes in height 
difference. The imposed suction was calculated as the difference between the air pressure applied on the sample's upper surface and the change of water level inside the inner tube. This method was applied for suctions up to $50 \mathrm{kPa}$, the air entry value of the ceramic disk used.

\subsubsection{Hydraulic conductivity}

The determination of the hydraulic conductivity function (HCF) started in saturated state by imposing a constant pressure head using a Mariotte bottle (that also allowed for water flow measurements through a graduated tube). In unsaturated states, the HCF was determined along he drying path of the WRC by applying suction steps and by monitoring the resulting changes in water content with time until equilibration by means of the differential pressure transducer. The calculation was based on Gardner's method [5], that is based on the hypothesis that the change in suction for each step is small, in such a way that the diffusion coefficient $D\left(h_{k}\right)$ can be considered constant during the test:

$$
D\left(h_{k}\right)=D=\frac{K\left(h_{k}\right)}{C\left(h_{k}\right)}=\frac{K\left(h_{k}\right) \Delta h_{k}}{\Delta \theta}
$$

where $C\left(h_{k}\right)$ is the average slope of the WRC along the suction step corresponding to $\Delta h_{k}, K\left(h_{k}\right)$ the hydraulic conductivity and $\theta$ the volumetric water content. Based on the analytical solution of the diffusion equation expressed in terms of a Fourier series, Gardner [5] proposed an estimation of the water conductivity using the monitored volume $V(t)$ of water extracted from the sample:

$$
V(t)=V_{\infty}\left(1-\frac{8}{\pi^{2}} \sum_{n=1,3,5, \ldots}^{\infty} \frac{1}{n^{2}} e^{-\left(\frac{n}{2}\right)^{2} \pi^{2} \frac{t}{T}}\right)
$$

with

$$
T=\frac{H_{\text {sample }}^{2} C\left(h_{k}\right)}{K\left(h_{k}\right)}=\frac{H_{\text {sample }}{ }^{2}}{D}
$$

where $V_{\infty}$ is the total amount of water extracted during the suction step. We observed that the sample height $H_{\text {sample }}$ remained reasonably constant and equal to 2.4 $\mathrm{cm}$.

According to Gardner [5], only the first member of the Fourier series in Equation (2) can be taken into account as a reasonable approximate solution, acceptable after $t>t_{\text {bound }}=\frac{4 H_{\text {sample }}{ }^{2}}{3 \pi^{2} D}$.

Equation (5) then becomes:

$$
\ln \left[V_{\infty}-V(t)\right]=\ln \frac{8 V_{\infty}}{\pi^{2}}-\pi^{2} \frac{D t}{4 H_{\text {sample }}{ }^{2}}
$$

showing that the term $\ln \left[V_{\infty}-V(t)\right]$ is a linear function of time $t$, with a slope depending on the diffusion coefficient $D$, providing the hydraulic conductivity $K\left(h_{k}\right)$ :

$$
K\left(h_{k}\right)=\frac{D \Delta \theta}{\Delta h_{k}}
$$

When the permeability of the ceramic disk is significantly smaller than that of the specimen, impedance effect have to be accounted for, which was done by using Kunze and Kirkham (1962)'s method [6], that is based on the use of charts providing the solution of the consolidation of a multilayers specimen with various permeability in each layer. Their solution is graphically presented through various curves showing the changes in $V(t) / \mathrm{V}_{\infty}$ with respect to the variable $\lambda_{l}^{2} D t / H_{\text {sample }}{ }^{2}$ (see Figure 5), in which the parameter $\lambda_{l}$ is the first solution of equation $a \lambda_{n}=\cot \lambda_{n}$ and $a$ is the ratio between the impedance of the ceramic disk and that of the sample. The various curves in Figure 5 correspond to various values of parameter $a$.

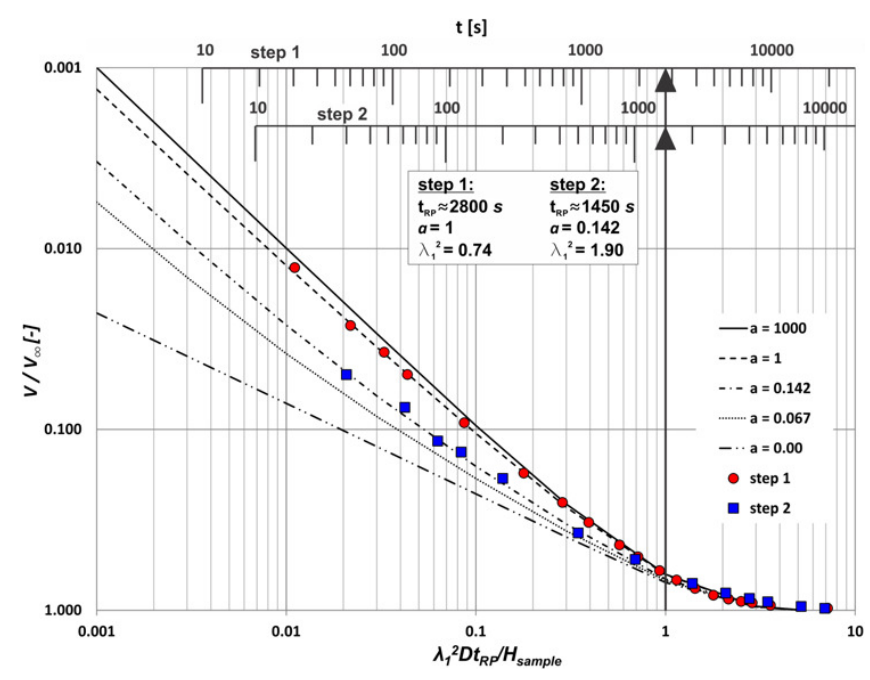

Fig. 5. Kunze and Kirkham's method.

The hydraulic conductivity $K\left(h_{k}\right)$ is derived from estimating $a$ and $\lambda_{1}$ by fitting experimental data with one of the theoretical curves, as done in Figure 5 for two imposed suction steps (more details later). It is also necessary to graphically determine the reference time $t_{R P}$ that corresponds to $\lambda_{l}^{2} \mathrm{Dt} / \mathrm{H}_{\text {sample }}{ }^{2}=1$ (vertical arrow in Figure 5). Finally, the diffusion coefficient is calculated as $D=H_{\text {sample }}^{2} / \lambda_{l}^{2} t_{R P}$ and the hydraulic conductivity as $K=D \Delta \theta / \Delta h_{0}$.

\section{Experimental results}

\subsection{Water retention curve}

Fig. 6 shows the changes in water level monitored when using both the hanging column technique (steps 1 to 10) and the axis translation technique (steps 11 to 13). 


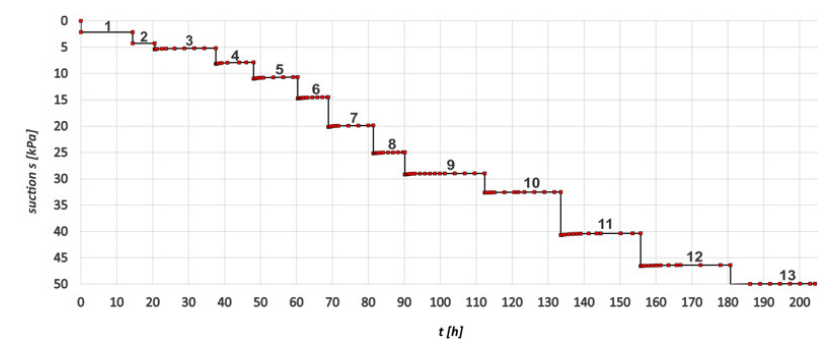

Fig. 6. Suction steps imposed along the drying path.

The outer tube was used for steps 1 and 2 (larger water volumes, valve V4 closed, valve V5 opened, see Fig. 3) while the subsequent 11 steps $(3-13)$ were made by using the inner tube (valve V4 opened, valve V5 closed). The drying path of the WRC is presented in Figure 7 in terms of change in volumetric water content with respect to suction.

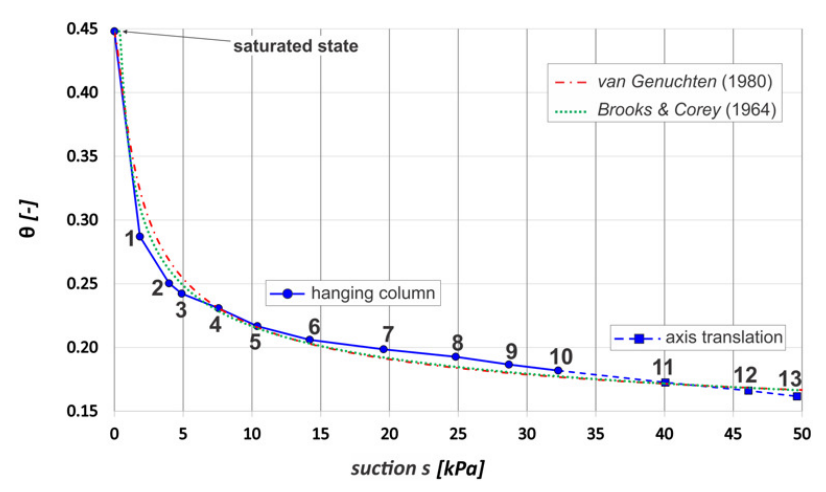

Fig. 7. Drying path of the water retention curve.

One observes a significant decrease in water content for the initial steps at low suctions, with $\theta$ decreasing from the initial value of 0.395 down to 0.23 under the first suction step of $2.1 \mathrm{kPa}$. The change in volumetric water content progressively decreases afterwards, with a decrease in $\theta$ to 0.20 at a suction of $4.2 \mathrm{kPa}$. The curve finally becomes almost linear at suction larger than $14.2 \mathrm{kPa}$, indicating that the further suction increments extract small quantities of water. A final value of 0.11 is reached at $49.6 \mathrm{kPa}$. Good comparability is observed between the section obtained with the hanging column technique $(1-10)$ and with the axis translation method $(11$ - 13). The WRC formulation of van Genuchten (1980) and Brooks and Corey (1964) are used:

$$
\mathrm{vG}: \theta=\theta_{\mathrm{r}}+\frac{\theta_{\mathrm{s}}-\theta_{\mathrm{r}}}{\left[1+\left(\alpha \mathrm{h}_{\mathrm{k}}\right)^{\mathrm{n}}\right]^{\mathrm{m}}} ; \text { with } \mathrm{m}=1-\frac{1}{\mathrm{n}}
$$

where $\theta_{s}=0.395$ is the saturated volumetric water content, $\theta_{r}=0.057$ the residual one, $\alpha=1 / h_{a}\left[\mathrm{~L}^{-1}\right]$ where $h_{a}=3.2 \mathrm{~cm}$ is the air entry value expressed in water height, and $n=1.35$;

$$
\mathrm{BC}: \theta=\theta_{r}+\left(\theta_{s}-\theta_{r}\right)\left(\frac{h_{k}}{h_{a}}\right)^{-\lambda}
$$

with $\lambda$ related to $n$ by the relation $\lambda=n-1=0.35$.

\subsection{Hydraulic conductivity}

Steady state measurements provided a saturated hydraulic conductivity $K_{s}=8.11 \times 10^{-6} \mathrm{~m} / \mathrm{s}$ for the specimen and $K_{c s}=4.02 \times 10^{-8} \mathrm{~m} / \mathrm{s}$ for the ceramic disk.

Figure 5 presents the experimental data of steps 1 and 2 in terms of changes in $V(\mathrm{t}) / V_{\infty}$ with respect to a $\log$ scale of $\lambda_{1}^{2} D t_{\mathrm{RP}} / H_{\text {sample, }}$ as proposed by Kunze and Kirkham, with excellent agreement between data and the theoretical curve for $a=1$.

A hydraulic conductivity $K(s)=2.14 \times 10^{-7} \mathrm{~m} / \mathrm{s}$ is obtained at $2.1 \mathrm{kPa}$, confirming the need of accounting for impedance effects due to the ceramic disk of smaller hydraulic conductivity $\left(K_{c s}=4.02 \times 10^{-8} \mathrm{~m} / \mathrm{s}\right)$.

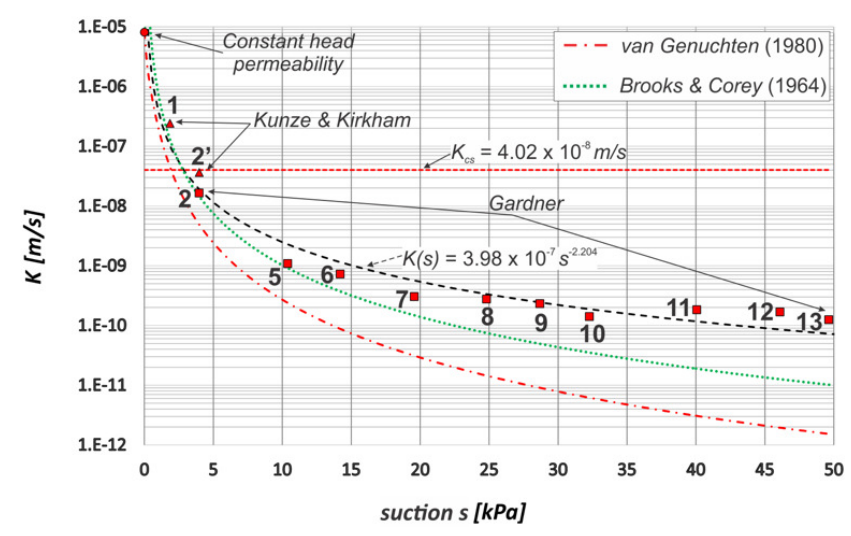

Fig. 8. Hydraulic conductivity function along the drying path.

Figure 8 shows the hydraulic conductivities along the drying path obtained using the three different methods: i) saturated hydraulic conductivity, using the constant-head permeability test, ii) unsaturated hydraulic conductivity at lower suctions, using Kunze and Kirkham's method (steps 1 and 2) and iii) unsaturated hydraulic conductivity at larger suctions, using Gardner's method [5] without accounting for any impedance effect (steps 2 ' and 5 to 13 ). The hydraulic conductivity at step 2' provided by Gardner's method [5] is somewhat smaller than that at step 2 given by Kunze and Kirkham's method. This is due to some impedance effect due to the lower permeability of the ceramic disk, indicating that Gardner's method is not fully satisfactory for step 2, since it measures the (lower) average hydraulic conductivity of the combination specimen + ceramic disk. Note however that the difference in hydraulic conductivity is not that large $\left(3.64 \times 10^{-8} \mathrm{~m} / \mathrm{s}\right.$ for Kunze and Kirkham and $1.64 \times 10^{-8} \mathrm{~m} / \mathrm{s}$ for Gardner's method). Overall, excellent comparability is observed etween the three different methods used, providing good confidence in the results obtained.

Figure 8 also presents the hydraulic conductivity values calculated from the WRC expressions according to Mualem (1970)'s approach, with the following expressions:

$$
\text { - vG: } K_{r}\left(h_{k}\right)=\frac{\left\{1-\left(\alpha h_{k}\right)^{n-1}\left[1+\left(\alpha h_{k}\right)^{n}\right]^{-m}\right\}^{2}}{\left[1+\left(\alpha h_{k}\right)^{n}\right]^{m / 2}}
$$

$$
\text { - BC: } K_{r}\left(h_{k}\right)=\left(\frac{h_{k}}{h_{a}}\right)^{-2-5 \lambda / 2}
$$


The Figure shows that both formulations underestimate the hydraulic conductivity, with a better correspondence observed with the Brooks and Corey formulation. This indicates that both expressions of the hydric conductivity function derived from WRC expressions, very often used in numerical calculations, might significantly under-estimate the real values.

An empirical power law expression has been fitted on the data of Figure 8 by using the root-mean-squaredeviation (RMSD) method:

$$
\mathrm{K}(\mathrm{s})=\mathrm{a}_{1} \times \mathrm{s}^{\mathrm{b}_{1}}
$$

with $a_{1}=5.38 \times 10^{-7}$ and $b_{1}=-2.283$.

\section{Conclusion}

The data provided by a new device for determining the water retention curve and the hydraulic conductivity function of a light coarse volcanic material used as substrate in an urban green roof has been presented. Both the hanging column (suction smaller than $32 \mathrm{kPa}$ ) and the axis translation (up to $50 \mathrm{kPa}$ ) techniques were used, providing good precision in both suction control and water content determination in the low suction range typical of coarse materials.

The system also allowed the accurate determination of the hydraulic conductivity function along the drying path, based on Gardner's method applied during the application of suction steps. When necessary, the impedance effect of the ceramic porous disk was accounted for by using Kunze and Kirkham's graphical method. The good comparability of the hydraulic conductivity values obtained at saturated state, by using Kunze and Kirkham [6] and Gardner's methods [5] provided good confidence in the data obtained.

Finally, the theoretical estimation, through Mualem's approach of the hydraulic conductivity functions obtained from the WRC expressions of van Genuchten and Brooks and Corey, quite often used in numerical modelling, appeared to provide some significant underestimation.

\section{References}

1. P.A.Versini, A. Gires, G. Fitton, I. Tchiguirinskaia, D. Schertzer, La Houille Blanche, (EDP Sciences)

4, 34 - 42 (2018)

2. XPP94-047, AFNOR Editions, Paris La Défense Cedex, 1998.

3. NFP94-056, French Standard, AFNOR Editions, Paris La Défense Cedex (1996)

4. NFP94-057, French Standard, AFNOR Editions, Paris La Défense Cedex (1992)

5. W. R. Gardner, Soil Sc. Soc. Proc. 20, 317 - 320 (1956)

6. R. J. Kunze, D. Kirkham, Soil Sci. Soc. Am. Proc. 26, 421 - 426 (1962) 